\title{
Rapid Induction of Orthotopic Hepatocellular Carcinoma in Mice by Fixed Puncture Point Injection
}

\author{
Rui Han ${ }^{1,2}$, Suihui $\mathrm{Li}^{1}$ and Lingeng $\mathrm{Lu}^{3 *}$ \\ ${ }^{1}$ Department of Oncology, The First Affiliated Hospital of Guangzhou University of Chinese Medicine, China \\ ${ }^{2}$ Department of Epidemiology and Public Health, Yale University School of Medicine, USA \\ ${ }^{3}$ Department of Chronic Disease Epidemiology, Yale School of Public Health, School of Medicine, Yale University, USA
}

*Corresponding author: Rui Han, Department of Oncology, The First Affiliated Hospital of Guangzhou University of Chinese Medicine, China. Email: dianxiqiao@foxmail.com, ORCID: 0000-0001-8856-3681.

To Cite This Article: Rui Han, Suihui Li, Lingeng Lu, Rapid Induction of Orthotopic Hepatocellular Carcinoma in Mice by Fixed Puncture Point Injection. Am J Biomed Sci \& Res. 2021 - 11(5). AJBSR.MS.ID.001665. DOI: 10.34297/AJBSR.2021.11.001665.

Received: 眥 November 24, 2020; Published: 眥 January 25, 2021

\begin{abstract}
Aim: Animal model is an indispensable tool in investigating the development, progression and treatment of human cancer including hepatocellular carcinoma (HCC). However, it is still challenging in establishing orthotopic HCC mouse models. Here, we presented a minimally invasive method with high tumor formation rate in mouse liver.

Methods: Hep3B-luc and SNU-449-luc HCC cells mixed with Matrigel were injected into the liver of nude mice from different source at fixed injection site and depth, respectively. The mice were divided into 3 groups. At fifteen days post-injection, the bioluminescence signal of liver tumor was detected and tumors in injected mouse liver were harvested. Cons and pros were then compared between presented and common approaches.

Results: We successfully developed an orthotopic transplantation tumor model in nude mice by directly injecting the mixture of Matrigel with tumor cell lines at fixed site. The tumor formation rate was $95 \%$ for all 20 mice and mice survival rate was $100 \%$ after implantation. The detection of fluorescent signals showed that tumors grew in mice with different rates. These fluorescent signal results were consistent with tumor volume results. Pathologic examination further confirmed that the tumors resected from mice liver were HCC.
\end{abstract}

Conclusion: A fixed site injection of the mixture of Matrigel and tumor cells is a convenient and efficient way with a high success rate and safety in establishing an orthotopic liver transplantation tumor model in mice.

\section{Introduction}

Hepatocellular carcinoma (HCC), a very common human malignancies, ranks the second leading cause of cancer-related death in the world, also the fastest-growing cause of cancer deaths in the United States, and the top six cause of death in China among all diseases [1,2]. Lacking early diagnosis method and effective therapy required more efforts to make on HCC treatment. Because of the physiologic and genetic similarities of rodents to human, rodents particularly nude mice are commonly used as models in pre-clinical cancer research experiments, in which the pathological process of human liver cancer and the microenvironment are simulated. To create orthotopic HCC model in mice, the hepatoma cells or tumor fragment must be implanted.
Laparotomy is a conventional approach in tumor implantation, and it has been prevalently employed in many studies, in which induced bioluminescence technique is used for repeated monitoring tumor status [3-5]. However, laparotomy was difficult to operate, timeconsuming and invasive. On the other hand, the experimental mice often suffer from adverse events such as bleeding, infection, and even death. Extensive postoperative nursing care is also necessary after the laparotomy approach. Some research groups have developed a better method to create orthotopic HCC (transplantable liver cancer) in mice under the guidance of ultrasound with less experiments-related adverse events compared to laparotomy $[4,6]$. However, due to the small size of mouse liver, it is prerequisite to 
have an expensive high-resolution ultrasound machine with a high frequency probe. Even though cancer cells can be directly injected and transplanted into lobe of the liver precisely under the guidance of ultrasound, the procedure still often readily cause bleeding. Therefore, it is important to establish a novel cheap rapid costeffective approach in HCC research.

Moreover, Matrigel is basement membrane-like extracellular matrix extract that has been used in a series of cancer research, such as facilitating liver tumor models [5]. It is a liquid at $4^{\circ} \mathrm{C}$, while it is gelled under physiological conditions at $24-37^{\circ} \mathrm{C}$ [7]. Matrigel has been reported to be used in orthotopic pancreatic tumor model to effectively prevent leakage from the injection point, improving tumor formation rate, and reducing the risk of intraperitoneal tumor implantation [8]. Whereas few studies have been proposed to improve HCC nude mice model with Matrigel in orthotopic xenograft HCC tumor model in mice. Therefore, we also applied Matrigel with the motivation to improve the HCC tumor formation rate and the safety.

\section{Materials and Methods}

\section{Cell culture and transduction of luciferase lentivirus}

SNU-449 and Hep3B cell lines were all purchased from American Type Culture Collection (ATCC, USA) in May 2019. Hep3B [5] was cultured in EMEM (ATCC, USA) with 10\% fetal bovine serum (FBS, Gibco, USA) and SNU-449 was cultured in RPMI-1640 medium, with $10 \%$ heat-inactivated FBS, respectively. Both of them were cultured in the same condition of humidified incubator at $37^{\circ} \mathrm{C}$ with 5\% CO2. Hep3B-luc and SNU-449-luc were then acquired by CMV-Firefly luciferase-IRES-Puro lentivirus transfection. For details, cell selection was conducted for at least 12 days with $1 \mu \mathrm{g} /$ $\mathrm{mL}$ puromycin. Stable fluorescence signal of both cell lines was confirmed by 96 microplate luminometer (Promega, USA). Two cell lines were both characterized using STR (Short Tandem Repeat) analysis for identity verification of human cell lines in 2019.

\section{Preparation of cell suspension for injection}

For preparing cell suspension, logarithmic growth phase of the SNU-449-luc (or Hep3B-luc) cells were centrifuged at 500g for 5min. After discarding the supernatant, $50 \mu \mathrm{l}$ medium (10\% FBS EMEM or RPMI-1640 medium) contained $5 \times 105$ cells (Hep3B-luc or SNU-449-luc) was then mixed with $50 \mathrm{ul}$ Matrigel at $4{ }^{\circ} \mathrm{C}$ by vortex [9]. The mixture without air bubble was then aspirated with a 1.5 $\mathrm{ml}$ syringe equipped with $30 \mathrm{~g}$ needle and stored in $4^{\circ} \mathrm{C}$ refrigerator. The whole mixture preparation process was recommended to carried out in a $4^{\circ} \mathrm{C}$ chamber.

\section{Animals}

5-6 weeks old male Athymic nude mice, weighing 18-21g, level SPF, were ordered from The Jackson Laboratory (USA) and Charles river (USA), respectively. 5 mice were ordered from The
Jackson Laboratory (USA) and 5 from Charles river (USA) at first for preliminary experiment, other 10 mice were then purchased from The Jackson Laboratory (USA) again. Mice were fed by the animal center of School of Public Health of Yale University under specific pathogen-free conditions and were provided with standard food and given free access to sterilized water. All mice were fed 1 week before the injection to adapt the environment. Experimental protocols were approved by the Yale University Institutional Animal care and Use Committee (IACUC), and experiments were carried out strictly to the approved guidelines. The first batch of Charles river 5 mice and Jackson Laboratory mice were divided as group $A$ and B, respectively. Other 10 mice from The Jackson Laboratory were signed as group $C$. Mice in group $A$ and $C$ were implanted with Hep3B-luc, SNU-449-luc for group B. respectively.

\section{Surgical procedure for orthotopic tumor model}

Orthotopic tumors were established by the direct intrahepatic injection of SNU-449-luc or Hep3B-luc cells, respectively. After preparation of injected cell suspension, mice were anesthetized by $2 \%$ isoflurane in an anesthesia tank. The puncture site was then located $(2 \mathrm{~mm}$ below the angle between the mice xiphoid and the left rib, as showed in Figure 1A \& 1B). 10\% povidone iodine solution followed by $70 \%$ ethanol were used for disinfecting injection field of abdominal skin for three times. Then, the $28 \mathrm{G}$ needle was inserted towards mouse liver and into the liver parenchyma traversing. The depth of inserting was about $10 \mathrm{~mm}$, and the needle was inserted at a shallow angle $\left(15^{\circ}\right)$. Because of the greater brittleness of the liver tissue, when the needle was accurately inserted, there was an explicit feeling of breakthrough. After the breakthrough, slowly inject the cell mixture. Once the injection was finished, the needle was kept inside for about 10-20s for Matrigel to coagulate and prevent leakage, then the needle was slowly retracted, and gentle pressure was placed on the needle insertion site with disinfectant cotton stick for several seconds. Generally, blood on the head of needle indicated that the injection was successful (Figure 1C).

\section{Biological luminescence analysis experiment}

A solution of $15 \mathrm{mg} / \mathrm{ml}$ fresh Luciferin reagent in DPBS was prepared and filtered through a $0.2 \mathrm{um}$ filter. The injection volume received $150 \mathrm{mg}$ of luciferin/kg body weight per mouse. The Luciferin solution is administered by intraperitoneal injection. IVIS imaging can be performed after waiting for 10-15 minutes.

\section{Histologic evaluation}

Tumors in mice liver in Group C were resected and embedded in paraffin. $4 \mu \mathrm{m}$ sections were cut and stained with hematoxylin and eosin (HE) to be observed as study described [10].

\section{Results}

At day 1 post-surgery, all mice were alive after tumor implantation and even 15th after the implantation. The 
fluorescence signal intensity of 15th day (Figure 2A). There was no significant difference in bioluminescence among all groups (Group

A: $2.57 \pm 0.768$; Group B: $1.857 \pm 1.097$; Group C: $2.535 \pm 1.232$ )

(Figure 3A).

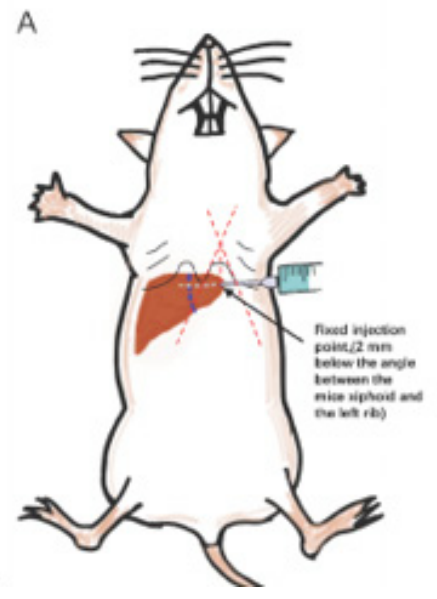

B

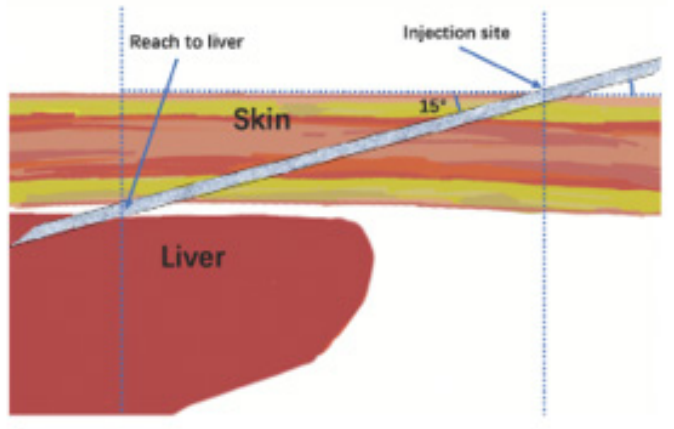

C

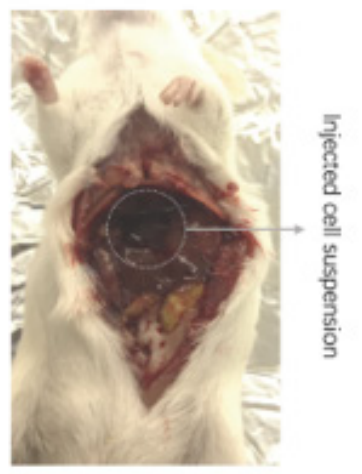

Figure 1: The fixed site for injection was located at $2 \mathrm{~mm}$ below the angle between the mice xiphoid and the left rib(A), The depth of inserting was about $10 \mathrm{~mm}$, and the needle was inserted at a shallow angle $\left(15^{\circ}\right)(B)$. The cell-Matrigel mixture was injected directly into liver percutaneously and formed a swelling in liver at the beginning(C).

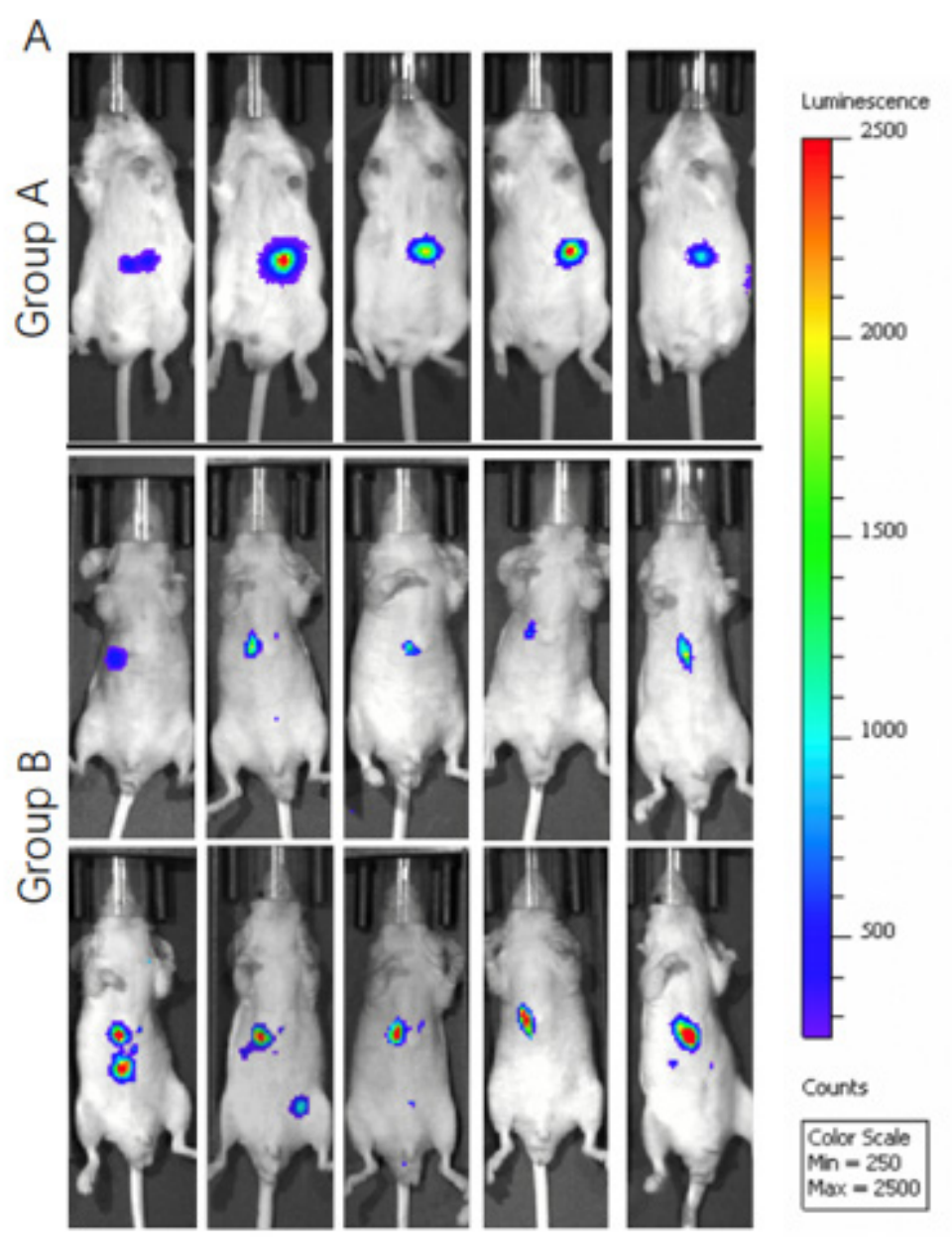

B

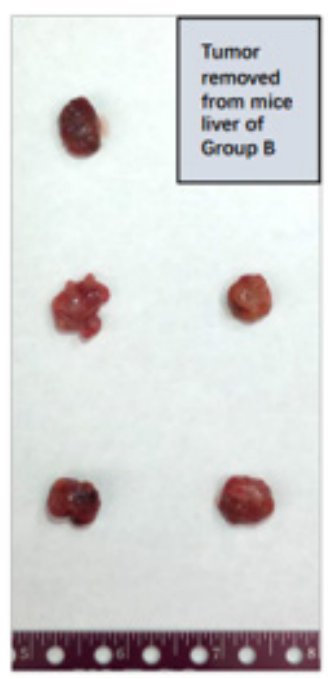

C

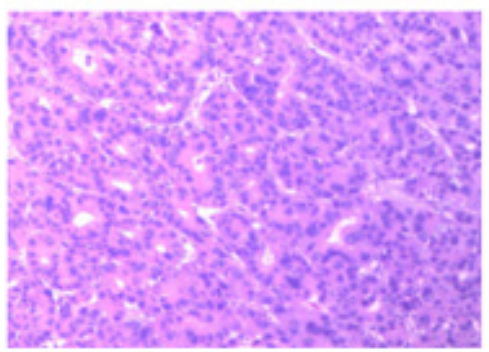

Tumor tissues from nude mice were detected by HE stain

Figure 2: The fluorescence signals in nude mice in Group A, B and C on the 15th day of implantation was detected by IVIS system(A). Harvesting orthotopic liver transplantation tumors was selected for tumor volume detecting(B). Tumors on nude mice liver from Group $C$ were detected by hematoxylin and eosin staining(C). 

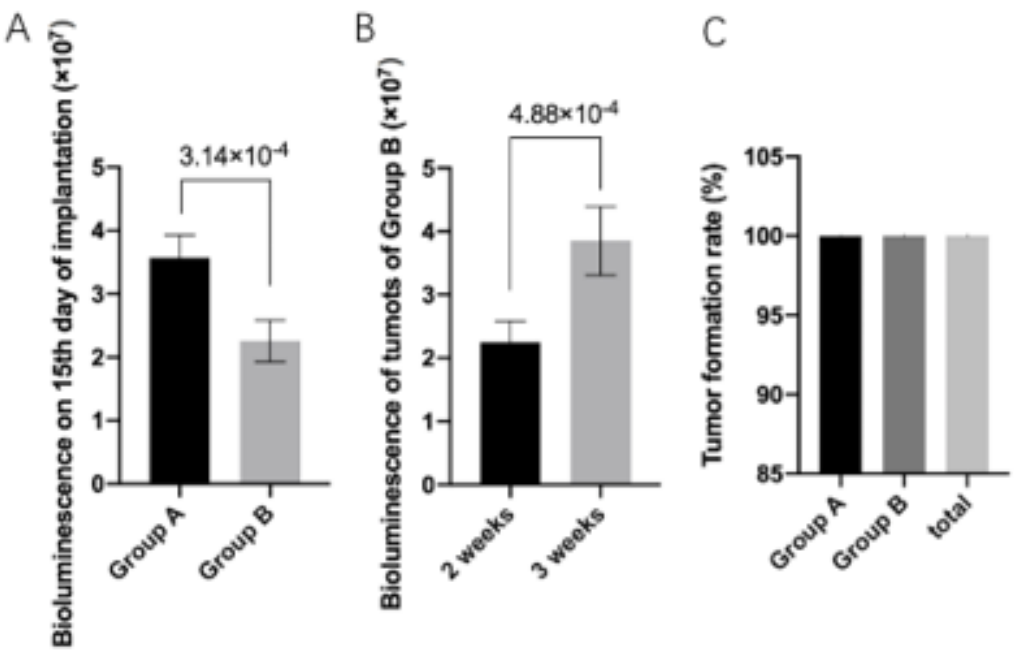

$\mathrm{D}$

Figure 3: The fluorescence signal intensity of liver tumor in each group showed nonsignificant differences between each other(A). Tumor formation rate was $100 \%$ in Group A and B, $90 \%$ for group C, and $95 \%$ for total mice(B). Volume of resected tumors from Group C were evaluated(C).

Table 1: Comparation between presented model method and other orthotopic model approaches.

\begin{tabular}{|c|c|c|c|c|c|}
\hline $\begin{array}{l}\text { Liver cancer or- } \\
\text { thotopic implan- } \\
\text { tation Method }\end{array}$ & $\begin{array}{l}\text { Tumor } \\
\text { formation } \\
\text { period }\end{array}$ & $\begin{array}{l}\text { Tumor for- } \\
\text { mation rate }\end{array}$ & Main purpose & Cons & Pros \\
\hline $\begin{array}{l}\text { Orthotopic im- } \\
\text { plantation of this } \\
\text { study }\end{array}$ & 15 days & $90-100 \%$ & $\begin{array}{l}\text { Research and drug } \\
\text { development for the } \\
\text { mechanism of liver } \\
\text { cancer growth and me- } \\
\text { tastasis; Study biologic } \\
\text { features of HCC in vivo } \\
\text { and to direct clinical } \\
\text { treatment }\end{array}$ & $\begin{array}{l}\text { Easily operated, timesaving, low-cost; } \\
\text { quicker recovery and lower risk of } \\
\text { postoperative complications; assess size } \\
\text { of the induced tumors and follow tumor } \\
\text { progression; appropriate for HCC metasta- } \\
\text { sis investigations; benefits research on the } \\
\text { interactions between the tumor and local } \\
\text { microenvironment; high safety }\end{array}$ & $\begin{array}{l}\text { Multiple cell lines need } \\
\text { to be tested }\end{array}$ \\
\hline $\begin{array}{l}\text { Normal orthot- } \\
\text { opic implantation } \\
\text { without matrigel } \\
\text { (laparotomy) }\end{array}$ & $\begin{array}{l}\text { 10days- } 2 \\
\text { weeks }\end{array}$ & $75 \%-100 \%$ & Same as above & High rate of tumor formation & $\begin{array}{l}\text { Hard to operate; trau- } \\
\text { matic postoperative } \\
\text { nursing care; high rate of } \\
\text { bleeding, mice death and } \\
\text { infection [16] }\end{array}$ \\
\hline $\begin{array}{l}\text { Orthotopic } \\
\text { implantation with } \\
\text { matrigel (laparot- } \\
\text { omy) }\end{array}$ & / & / & Same as above & $\begin{array}{c}\text { Appropriate for HCC metastasis investiga- } \\
\text { tions; benefits research on the interactions } \\
\text { between the tumor and local microenvi- } \\
\text { ronment }\end{array}$ & $\begin{array}{l}\text { Hard to operate; trau- } \\
\text { matic postoperative } \\
\text { nursing care; high rate of } \\
\text { infection [17] }\end{array}$ \\
\hline $\begin{array}{l}\text { Orthotopic } \\
\text { implantation } \\
\text { with ultrasound } \\
\text { plus fluorescence } \\
\text { imaging }\end{array}$ & 10 days & $60.40 \%$ & Same as above & $\begin{array}{l}\text { Quicker recovery and lower risk of } \\
\text { postoperative complications; Assess size } \\
\text { of the induced tumors and follow tumor } \\
\text { progression }\end{array}$ & $\begin{array}{l}\text { Technically complex; } \\
\text { uneconomical and hard } \\
\text { to popularize [17] }\end{array}$ \\
\hline $\begin{array}{l}\text { Hollow fibre } \\
\text { model }\end{array}$ & $1-2$ weeks & / & $\begin{array}{l}\text { Proof-of-principle; } \\
\text { drug screening }\end{array}$ & Reduce the amount of mice for research & $\begin{array}{l}\text { Cannot test complex } \\
\text { tumor-host interactions; } \\
\text { high cost [18] }\end{array}$ \\
\hline $\begin{array}{l}\text { Genetically } \\
\text { modified mouse } \\
\text { models (GMM) }\end{array}$ & $90-100$ weeks & / & $\begin{array}{l}\text { Evaluating the impacts } \\
\text { of oncogenes or } \\
\text { oncogenes with other } \\
\text { carcinogenic agents in } \\
\text { cancer development }\end{array}$ & $\begin{array}{l}\text { Can assess the roles of genes and relat- } \\
\text { ed pathways in tumor development and } \\
\text { carcinogenesis }\end{array}$ & $\begin{array}{l}\text { High cost; long period } \\
{[19]}\end{array}$ \\
\hline $\begin{array}{l}\text { Chemically in- } \\
\text { duced models }\end{array}$ & 45-104 weeks & $80-100 \%$ & $\begin{array}{c}\text { Study the biologic fea- } \\
\text { tures and mechanisms } \\
\text { of injury-fibrosis-ma- } \\
\text { lignancy }\end{array}$ & $\begin{array}{l}\text { Mimic the cycle of injury-fibrosis-malig- } \\
\text { nancy existed in humans }\end{array}$ & Long period [20] \\
\hline
\end{tabular}


As showed in Fig 3B, all mice in group A and B (10 in total) had been implanted with SNU-449 cells successfully with 100\% tumor formation rate on the 15th day after implantation. However, in group $\mathrm{C}$, tumor cells failed to grow and form in one mouse, and the tumor formation rate was $90 \%$ for group $\mathrm{C}$ at the same time point. The tumor formation rate was $95 \%$ for whole 3 groups (20 mice).

Tumors in mice of group C liver were resected and peeled off from mice liver on the 15th day of implantation and also right after IVIS test (Figure 2B). Surrounding tissues of the tumor in mice liver were euangiotic. The volume ( $\mathrm{mm} 3$ ) of each tumor in Group C was decided as the formula:

Tumor volume $=1 / 2$ (Length $\times$ Width2) $($ Figure $3 C)$ [11] .

Tumorigenesis was further confirmed by HE staining as showed in Figure 2C. Characteristics of liver cancer cell such as abnormal core, atypia, heteromorphic. cell form, nuclear division were observed.

\section{Discussion}

Research in hepatocellular carcinoma have raised furiously in the past decades since the morbidity of this disease kept climbing in the region of America and Asia [12,13]. This makes animal models more needs ever than before since it is an indispensable part of HCC research. At present, HCC can be successfully replicated in rats, nude mice, pigs and other animals, among them, nude mice are more likely to replicate the condition of HCC due to immunocompromise. Currently, several liver cancer modeling methods are often applied in HCC studies, such as orthotopic or ectopic transplantation, drug induction and transgenic model. Moreover, orthotopic model is superior to the ectopic model in the reconstruction of tumor microenvironment and organ tropism. However, there are some practical problems like high-cost, long period of tumor formation in those conventional methods.

Matrigel, as a matrix, has been used more in 3D culture of tumor cells as we reported previously [13]. Studies have shown that diluted matrigel can form a gel drip in the pancreatic parenchyma, effectively preventing leakage from the injection site, improving tumor formation rate, and reducing the risk of intraperitoneal tumor implantation in mouse model [8]. Matrigel provides a fixed framework for cells to grow. Moreover, with the help of Matrigel, the pressing time after injection has been reduced to several seconds compared several minutes in traditional approach for stop bleeding [14].

A novel way of orthotopic liver cancer modeling was presented in this study with fixed puncture site and needle depth which was believed to possess the characteristic of easy operation, timesaving and low-cost compared to the conventional methods with high safety and high tumor formation rate. The post-implantation survival rate of mice in presented method was 100\% compared to $60 \%$ of routine laparotomy method [15]. For establishing the model, cancer cells must be injected intrahepatically into the mice. The presented approach provided the short period for tumor formation (15 days) with $95 \%$ tumor formation rate. This technique is also a recommended method for proof-of-principle demonstration once enough cell lines have been tested. That was why two different HCC cell lines and even different nude mice were applied in this study. Once the injected cancer cells have been transfected with luciferase lentivirus, the tumor formed in liver has become clearly visible and accurately measurable with the help of IVIS has showed in Fig 2A, also the metastatic spread of the tumor could be observed. Moreover, this type of model has widely been used for drug therapeutic efficiency evaluation, toxicity, absorption and pharmacokinetics assessment in preclinical studies. It is thought to be beneficial to explore the pathogenesis of HCC and screen new drugs. Comparation between presented model method and other orthotopic model approaches was showed in (Table 1) and described as followed.

\section{Comparation between presented model method and other orthotopic model approaches}

Generally, mouse transplantation models often require open abdominal cavity and expose the left lobe of the liver for tumor cell suspension injection or invasive liver surgery. However, the surgical procedure is comparatively sophisticated, requiring special training, and the sterility requirement is high. Bleeding, infection and even death of mice frequently go along with laparotomy. Postoperative care is another issue. In addition, the success rate of modeling is study-dependent and the possibility of liver cancer cells to spread into the abdominal cavity or adjacent organs of the liver still exist. It has been shown that the laparotomy approach has an extremely high tumor formation rate of $100 \%$, short period latency, typical pathological characteristics and similar metastasis patterns [20]. Compared to this, our method presented more efficient and safer procedure which brought less damage to mice both physically and psychologically, and also still provided high tumor formation rate.

Ultrasound guided implantation is created to avoid direct laparotomy. However, the use of ultrasound requires massive financial support and extra technical training for ultrasound machine operation. Compared to such method, our modeling method is more cost-efficient and easier to operate without the need for professional training while the tumor formation time is similar. However, the injection site of our approach is fixed, that under ultrasound guided is adjustable.

As for chemically induced models, which demands the injection of carcinogenic compounds that are generally divided into genotoxic compounds and promoting compounds. The first one possessed the ability of inducing structural DNA changes and the second one could promote tumor formation after the intervention 
of hepatotoxic compound such as Peroxisome, Aflatoxin and CCl4 [21]. The chemicals-induced models take 45-104 weeks for tumor formation and used to mimic the cycle of injury-fibrosis-malignancy [22].

Genetically modified mouse models (GMM) are mainly used for evaluating the impacts of oncogenes or oncogenes with other carcinogenic agents in cancer development. This approach requires the establishment of transgenic mice which is high cost and is mainly used for assessing the roles of genes and related pathways in tumor development and carcinogenesis [23].

Xenograft model are mainly divided into three types. One is ectopic model which is established by subcutaneously injecting cancer cells in the flank of mice. One is hollow fiber assay (HFA) which extra requires the application of high-cost small semipermeable tubes and cannot test complex tumor-host interactions such as cancer metastasis. The other one is Genetically modified mouse models (GMM), a high-cost method which requires 90-100 weeks for tumor formation. The liver of the nude mice has a definite anatomical location, and the liver lobe is shallow in the upper abdomen.

Therefore, in this study, we accurately located the injection site of mice liver without the guidance of ultrasound. In the present study, after 15 days of cell suspension injection, IVIS system was used to detect the fluorescence signal of implanted tumor, the tumor formation rate was achieved 95\%. Combined with the ingenious application of matrigel, orthotopic implantation, fluorescence imaging, this method has been proved to be a reliable tool for establishing an HCC model in mice with acceptable tumor formation rate and safety, which might be widely used as an improved convenient HCC modeling method to promote liver cancer research. One thing should be noticed is that multiple cell lines should be used when conducting proof-of-principle study due to the remarkable variations in cancer cell phenotypes of different cell lines. However, this shortcoming could be partly fix by using biopsy sample (PDX model) [24].

\section{Declarations}

\section{Ethics approval and consent to participate.}

Mice were fed by the animal center of School of Public Health of Yale University under specific pathogen-free conditions and were provided with standard food and given free access to sterilized water. Experimental protocols were approved by the Yale University Institutional Animal care and Use Committee (IACUC), and experiments were carried out strictly to the approved guidelines.

\section{Availability of Data and Material}

All row date is available.

\section{Acknowledgement}

None.

\section{Funding}

None.

\section{Authors' Contributions}

Dr. Han and Dr. Lu designed the research. Dr. Han conducted the animal experiments. Dr. Han and Dr. Zhao performed data analysis. All authors contributed to manuscript writing.

\section{Competing interests}

None.

\section{References}

1. Zhou M, Haidong Wang, Xinying Zeng, Peng Yin, Jun Zhu, et al. (2019) Mortality, morbidity, and risk factors in China and its provinces, 19902017: a systematic analysis for the Global Burden of Disease Study 2017. Lancet 394(10204): 1145-1158.

2. Han R, Shixin Li (2018) Regorafenib delays the proliferation of hepatocellular carcinoma by inducing autophagy. Pharmazie 73(4): 218-222.

3. Kobayashi M, Cheng Long Huang, Makoto Sonobe, Ryutaro Kikuchi, Hiroshi Date, et al. (2016) Ad-shWnt2b Vector Therapy Demonstrates Antitumor Activity in Orthotopic Intrapleural Models as Monitored with the In Vitro Imaging System (IVIS). Anticancer Res 36(11): 5887-5893.

4. Chan HH, Tian Huei Chu, Hsin Fan Chien, Cheuk Kwan Sun, E Ming Wang, et al. (2010) Rapid induction of orthotopic hepatocellular carcinoma in immune-competent rats by non-invasive ultrasound-guided cells implantation. BMC Gastroenterol 10: 83.

5. Liu W, Qian Zhang, Qin Tang, Changpeng Hu, Jingbin Huang, et al. (2018) Lycorine inhibits cell proliferation and migration by inhibiting ROCK1/ cofilininduced actin dynamics in HepG2 hepatoblastoma cells. Oncol Rep 40(4): 2298-2306.

6. Han R, Chen XY (2019) Apoptotic protease activating factor-1 negatively regulates Wnt signaling in hepatocellular carcinoma. Kaohsiung J Med Sci 35(8): 459-466.

7. Kleinman HK, Martin GR (2005) Matrigel: basement membrane matrix with biological activity. Semin Cancer Biol 15(5): 378-386.

8. Jiang YJ, Chong Lek Lee, Qiang Wang, Zhong-Wen Zhou, Feng Yang, et al. (2014) Establishment of an orthotopic pancreatic cancer mouse model: cells suspended and injected in Matrigel. World J Gastroenterol 20(28): 9476-9485.

9. Alabi BR, LaRanger R, JW Shay (2019) Decellularized mice colons as models to study the contribution of the extracellular matrix to cell behavior and colon cancer progression. Acta Biomater 100: 213-222.

10. Yu J, Alex Y Hui, Eagle S H Chu, Alfred S L Cheng, Minnie Y Y Go, et al. (2007) Expression of a cyclo-oxygenase-2 transgene in murine liver causes hepatitis. Gut 56(7): 991-999.

11. Jensen MM, Jesper Tranekjaer Jørgensen, Tina Binderup, Andreas Kjaer, et al. (2008) Tumor volume in subcutaneous mouse xenografts measured by microCT is more accurate and reproducible than determined by 18F-FDG-microPET or external caliper. BMC Med Imaging 8: 16.

12. (2017) Nivolumab plus Ipilimumab Is Well Tolerated and Active in NSCLC. Cancer Discov 7(2): 124.

13. Han R, Xinyi Chen, Ya Li, Shunjia Zhang, Ruibai Li, et al. (2019) MicroRNA-34a suppresses aggressiveness of hepatocellular carcinoma by modulating E2F1, E2F3, and Caspase-3. Cancer Manag Res 11: 29632976.

14. Brown ZJ, Heinrich B, Greten TF (2018) Establishment of Orthotopic Liver Tumors by Surgical Intrahepatic Tumor Injection in Mice with Underlying Non-Alcoholic Fatty Liver Disease. Methods Protoc 1(2): 21. 
15. Zhao GJ, Li-Xia Xu, Eagle S H Chu, Ning Zhang, Jia-Yun Shen, et al. (2012) Establishment of an orthotopic transplantation tumor model of hepatocellular carcinoma in mice. World J Gastroenterol 18(47): 70877092 .

16. Heindryckx F, Colle I, Van Vlierberghe H (2009) Experimental mouse models for hepatocellular carcinoma research. Int J Exp Pathol 90(4): 367-386.

17. He L, DeAn Tian, Pei Yuan Li, Xing-Xing He (2015) Mouse models of liver cancer: Progress and recommendations. Oncotarget 6(27): 2330623322.

18. Decker S, M Hollingshead, C A Bonomi, J P Carter, E A Sausville (2004) The hollow fibre model in cancer drug screening: the NCI experience. Eur J Cancer 40(6): 821-826.

19. Haemmerle G, Lass A (2019) Genetically modified mouse models to study hepatic neutral lipid mobilization. Biochim Biophys Acta Mol Basis Dis 1865(5): 879-894.
20. Finnberg N, El Deiry WS (2004) Activating FOX03a, NF-kappaB and p53 by targeting IKKs: an effective multi-faceted targeting of the tumor-cell phenotype? Cancer Biol Ther 3(7): 614-616.

21. Gao YS, Xiao Ping Chen, Kai Yan Li, Zai De Wu (2004) Nude mice model of human hepatocellular carcinoma via orthotopic implantation of histologically intact tissue. World J Gastroenterol 10(21): 3107-3111.

22. Pitot HC, Dragan YP (1991) Facts and theories concerning the mechanisms of carcinogenesis. FASEB J 5(9): 2280-2286.

23. Takashima M (2008) [Achromatic watercolor effect: about requirement of formation of sumi painting effect]. Shinrigaku Kenkyu 79(4): 379-384.

24. Hu B, Hong Li, Wei Guo, Yun Fan Sun, Xin Zhang, et al. (2020) Establishment of a hepatocellular carcinoma patient-derived xenograft platform and its application in biomarker identification. Int J Cancer 146(6): 1606-1617. 